\title{
PERFORMANCE OF SLOPE UNDER SEISMIC CONDITIONS
}

\author{
Rajani Shurpali $^{1}$, L Govindaraju ${ }^{2}$ \\ ${ }^{l}$ Assistant Professor, Dept. of Civil Engineering Sri Venkateshwar College of Engineering, Bangalore, Karnataka, India \\ ${ }^{2}$ Associate Professor, Dept. of Civil Engineering, UVCE, Bangalore University, Bangalore, Karnataka, India
}

\begin{abstract}
The seismic stability of earth slopes has been a topic of considerable interest in geotechnical engineering practice for the past few decades. The failure of slopes during earthquakes can lead to the significant losses. The seismic stability of slopes is influenced by many factors and complete slope stability evaluation must consider the effects of each like geological, hydrological, topographical, geometrical, strong ground motion parameters during an earthquake and soil characteristics all influence the stability of a slope. Hence, the seismic performance of these structures requires appropriate evaluation during their design. Such performance is best evaluated through an assessment of the potential for seismically induce permanent displacements. This paper presents numerical studies on response of unreinforced slopes due to dynamic loading based on finite element analysis. Model embankments of silty sand and clayey sand have been considered. The parameters selected for the dynamic analysis includes embankment of height $5 \mathrm{~m}$ and $12 \mathrm{~m}$ with gentle slope 300 and steep slope 500. The sub base depth $(D)$ is varied with height of the slope $(H)$ with $D / H$ ratio from 0.5 to 2.0.The various past earthquake records are considered with different amplitudes ranging from $0.1 \mathrm{~g}$ to $0.4 \mathrm{~g}$.The results are presented in the form of factor of safety against slope failure under static and seismic conditions and settlement of crest of slopes. It is observed that as the height of the slope increases the maximum crest displacement increases for both type of soil and sub soil conditions.
\end{abstract}

Keywords: Amplitude, Earthquake ground motion, Slope, Settlement, etc $* * *$

\section{INTRODUCTION}

Earthquakes are the one of the most devastating natural hazards in the world they causes a great loss of life and property every year. The countries in earthquake prone area suffer a lot due to frequent medium to large-scale earthquakes. Earthquakes can play a triggering role for the slope stability problems as well and can reactive the old landslides bringing about the sequence of disaster. Analysis of the static and seismic stability of natural and manmade slopes is a challenging geotechnical problem. Often, different professionals analyzing the same problem will estimate a wide variation in expected performance. That variation results from variable levels of care in site exploration, laboratory testing, and the performance of stability analyses.Previously, many studies on the response of slopes have been carried out based on experimental and numerical analysis by various researchers (Ambraseys N \& Srbulov M, 1995; Ashford,S.A \& Sitar N, 2002; Bijan Khazai \& Nicholas Sitar,2000; Griffiths D.V, \& Lane P.A. 1999; Ka-Ching San \& Lovlesh Chinsky, 1994; Sawada T et al. 1993; Tan D \& Sarma S.K 2008; Radoslaw L. Michalowski and Liangzhi You,1999; Debabrata Giri and Aniruddha Sengupta.

In the present study, the numerical analyses of model slopes have been carried out based on finite element procedure using the Geo Studio software. The effect of ground motion parameters such as amplitude and frequency of vibrations for the past history earthquake data like Bhuj earthquake and Northridge earthquake.

\subsection{Parametric Studies:}

Sand and clay model embankments of height (D) $5 \mathrm{~m}$ and the ratio of depth of sub base $(\mathrm{H})$ to the height of the slope (D), $\mathrm{H} / \mathrm{D}$ ratio are also considered for various slope $0.5,1.0,1.5$ and 2.0 as shown in Fig. 1 are considered. Both the models were studied for two slope angle $(\theta)$ gentle slope $30^{\circ}$ and steep slope $50^{\circ}$. The properties of soil have been given in Table 1 .

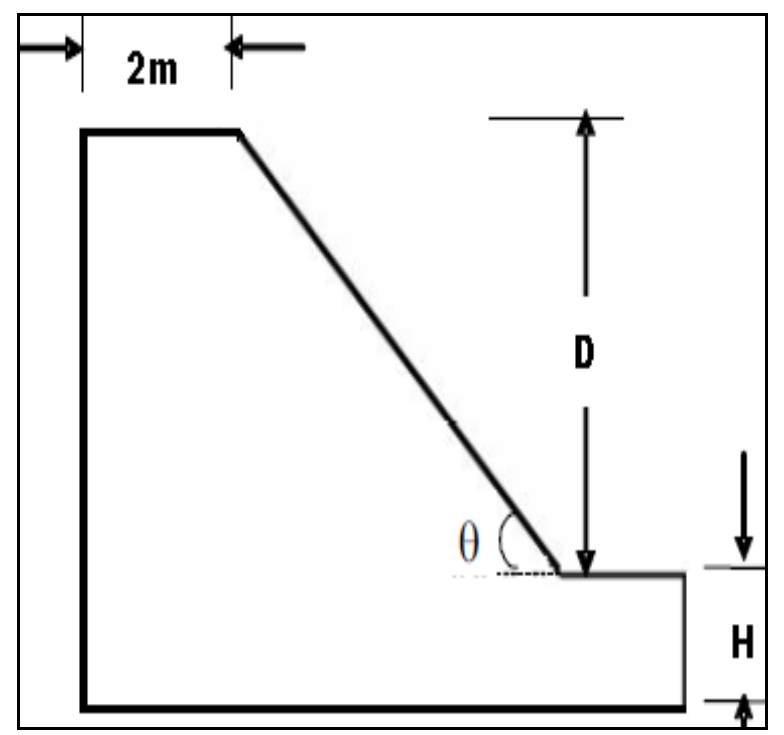

Fig 1: Typical embankment with slope angle $(\theta)$ 
Table 1: Properties of Soil

\begin{tabular}{|l|l|l|}
\hline Soil Type & Silty Sand & Medium Clay \\
\hline Cohesion,c kPa & 1 & 24 \\
\hline Angle of Friction $(\theta)$ & 20 & 5 \\
\hline Poisson's Ratio $(\mu)$ & 0.3 & 0.3 \\
\hline $\begin{array}{l}\text { Static young's modulus ( } \\
\text { MPa) }\end{array}$ & 18 & 28.7 \\
\hline $\begin{array}{l}\text { Dynamic shear modulus } \\
(\mathrm{MPa})\end{array}$ & 24 & 30 \\
\hline
\end{tabular}

\subsection{Numerical Analysis}

Numerical analyses of the embankments in static and dynamic conditions were carried out using finite element procedure employing computer program Geo Studio. The analyses of the both soil models was carried out based on Mohr Coulomb yield criteria. The embankments were discretised by iso parametric elements. In the static condition, gravity analysis was performed and the stresses are allowed to reach equilibrium state under self weight only by applying appropriate boundary conditions. The boundary at the bottom of the embankment was fixed. The two vertical side boundaries were assumed to be on roller allowing for vertical deformation. Dynamic analyses of the embankments were carried out using QUAKE/W. In dynamic analysis, the two vertical side boundaries were made free to allow deformations and fixed at the base in order to simulate the field condition. The vertically propagating seismic waves from base of the embankment that reaches the crest of the embankment induce the displacements.

Initially, static analysis has been carried out to check the stability of the slope in terms of factor of safety. The analyses were carried out for both silty sand and medium clay embankments. Table $\mathbf{2}$ shows the stability of slopes in terms of factor of safety embankments of silty sand and medium clay. It is observed that the slopes are stable under static condition for slope angles $30^{\circ}$ and $50^{\circ}$ for both types of embankments.

\section{DYNAMIC ANALYSIS}

The dynamic analyses have been carried out on embankments of both silty sand and medium clay materials using various ground motions for past history earthquake Northridge and Bhuj earthquakes $25 \mathrm{~s}$ and $134 \mathrm{~s}$ respectively as presented in fig 2a,b c, d and fig 3a,b,c,d respectively. These ground motions were excited at the base of the embankment and the resulting deformations at the crest of the embankments due to propagation seismic waves were evaluated. It is observed that, as the amplitude of acceleration increases and ratio of depth of sub base $(\mathrm{H})$ to the height of the slope (D), H/D ratio increases, the magnitude of the crest settlement increases at a given frequency.

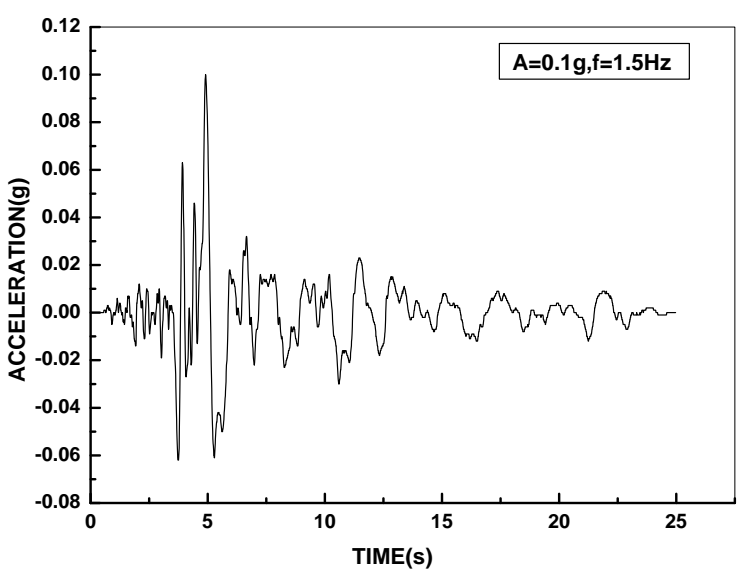

(2a)

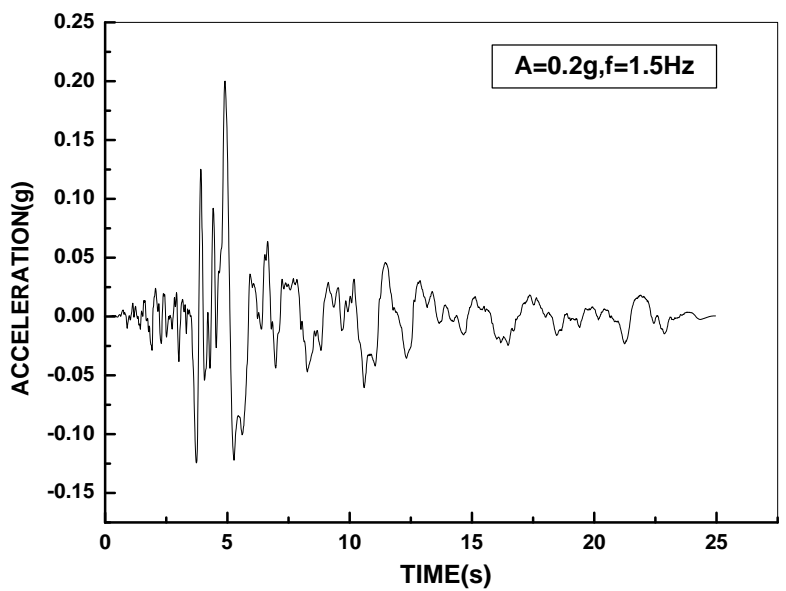

(2b)

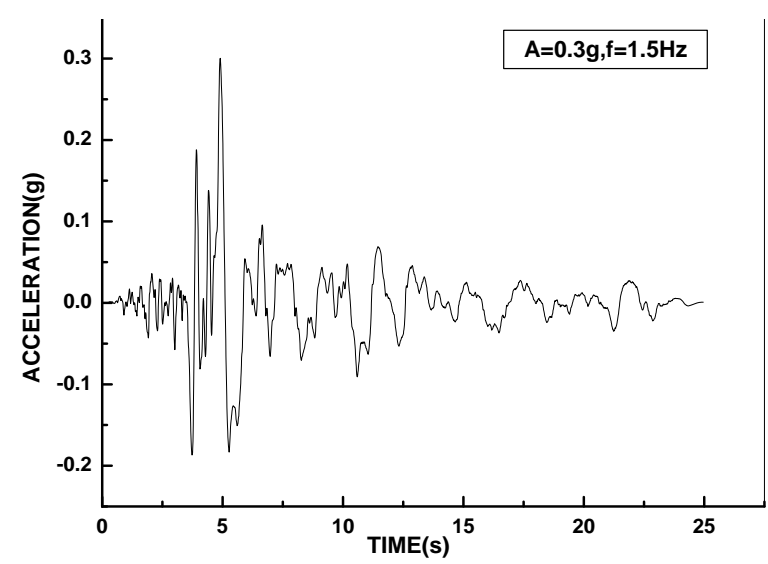

(2c) 


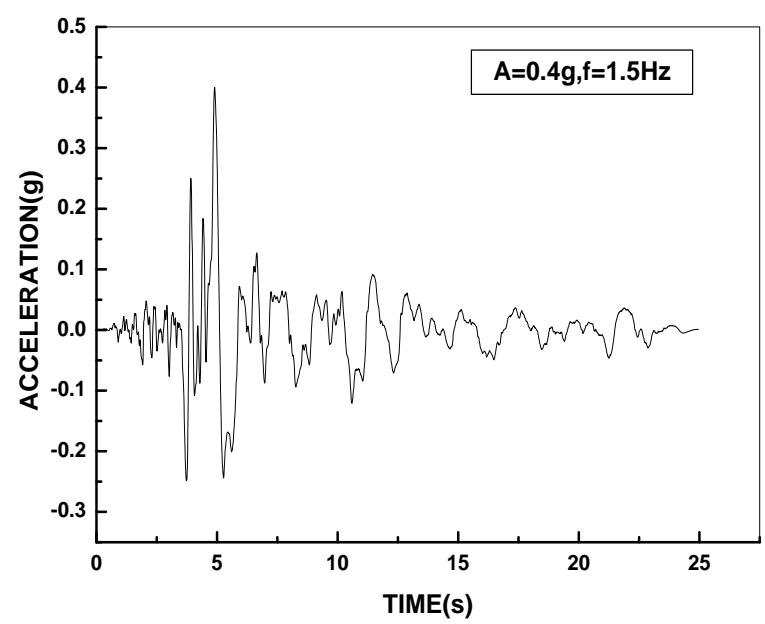

(2d)

Fig 2: Northridge Earthquake motion for varying amplitude

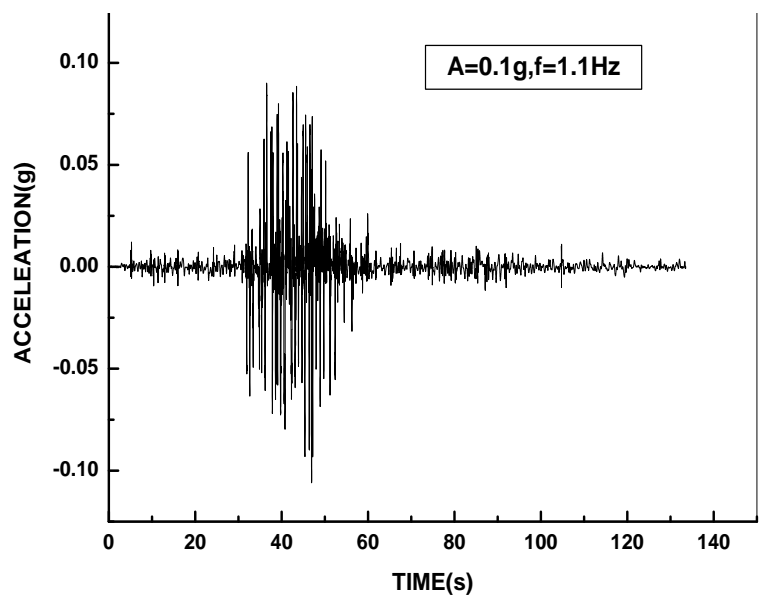

(3a)

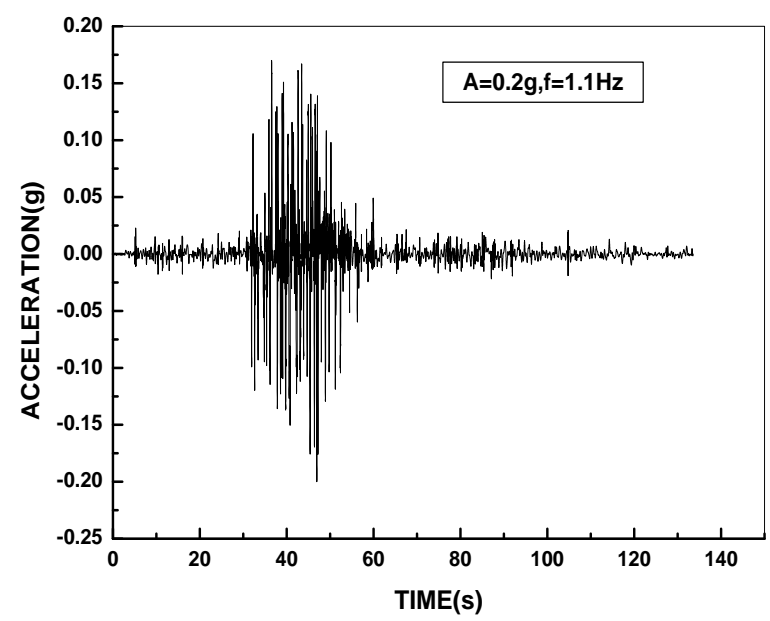

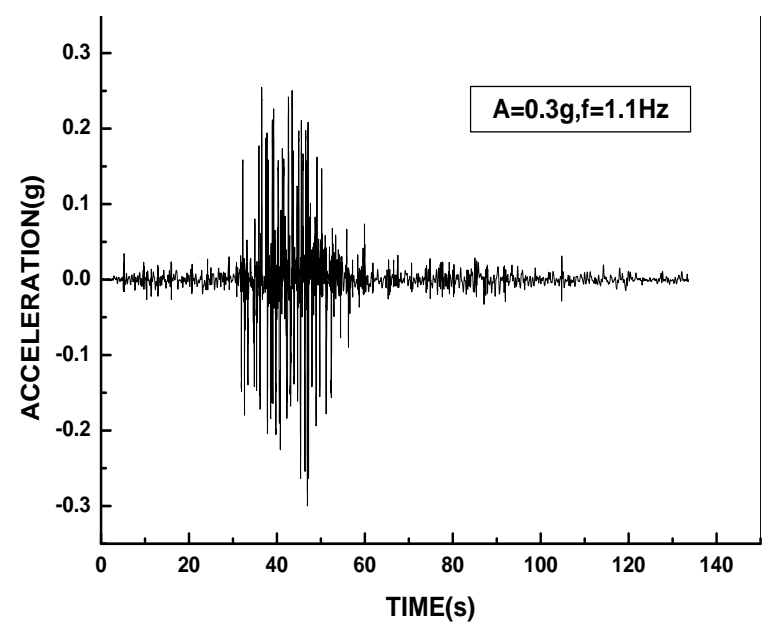

(3c)

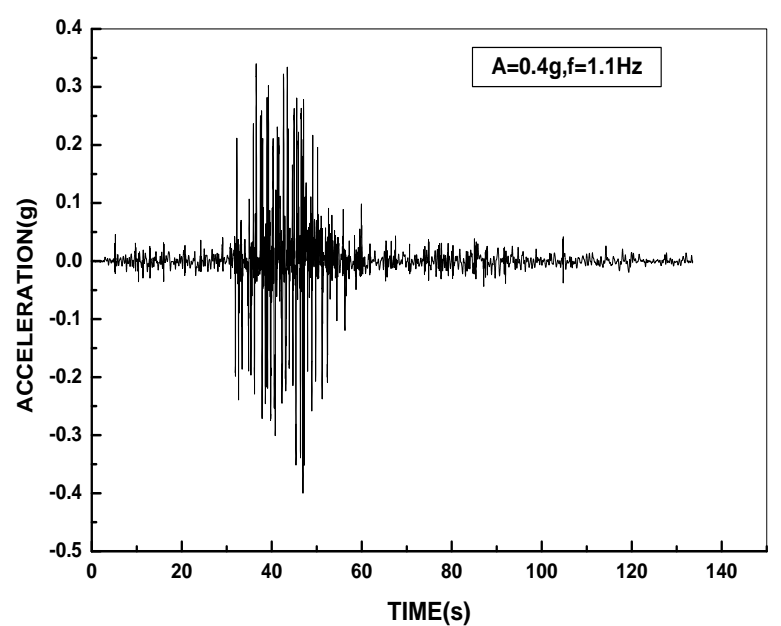

(3d)

Fig 3: Bhuj Earthquake motion for varying amplitude

Fig 4 shows the Variation of Max Crest Displacement Vs Acceleration for Northridge Earthquake, $30^{\circ} \& 50^{\circ}$, silty sand. It is observed that as the amplitude of acceleration increases and $\mathrm{H} / \mathrm{D}$ ratio, magnitude of displacement increases. Also as the inclination of slope increases the displacement increases. Table $3 \&$ 4gives the comparison of factor of safety of slope under static and dynamic conditions

(3b) 


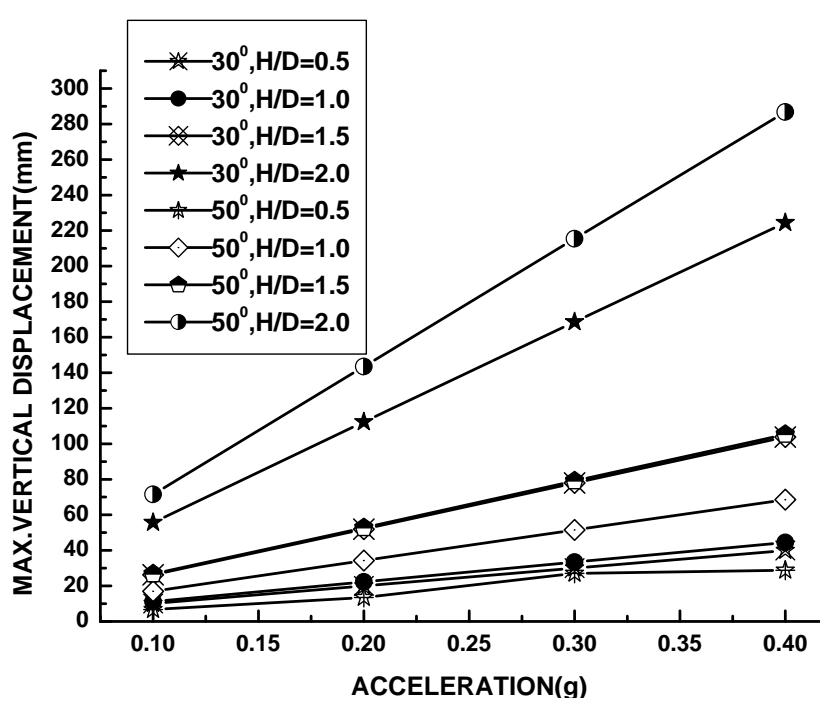

Fig 4: Variation of Max.Crest Displacement Vs Acceleration for Northridge Earthquake, $30^{\circ} \& 50^{\circ}$, silty sand.

Fig 5 shows the Variation of Max Crest Displacement Vs Acceleration for Bhuj Earthquake, $30^{\circ} \& 50^{\circ}$, silty sand. It is observed that increase in amplitude of acceleration increase in crest settlement. However, it is interesting to note that for H/D ratio1.5 for $50^{\circ}$ slope, maximum crest displacement is observed. This may be attributed to the close matching of the excitation frequency with the natural frequency of the embankment.

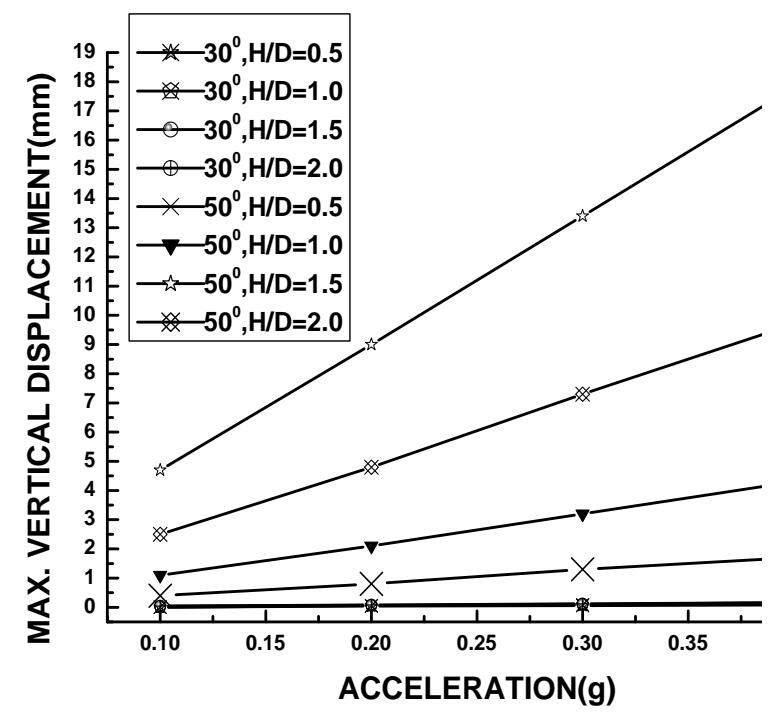

Fig 5: Variation of Max.Crest Displacement Vs Acceleration for Bhuj Earthquake, $30^{\circ} \& 50^{\circ}$, silty sand.

Fig 6 shows the Variation of Max Crest Displacement Vs Acceleration for Northridge Earthquake, $30^{\circ} \& 50^{\circ}$, Medium Clay. It is observed that as the amplitude of acceleration increases and H/D ratio, magnitude of displacement increases.
Also as the inclination of slope increases the displacement increases.

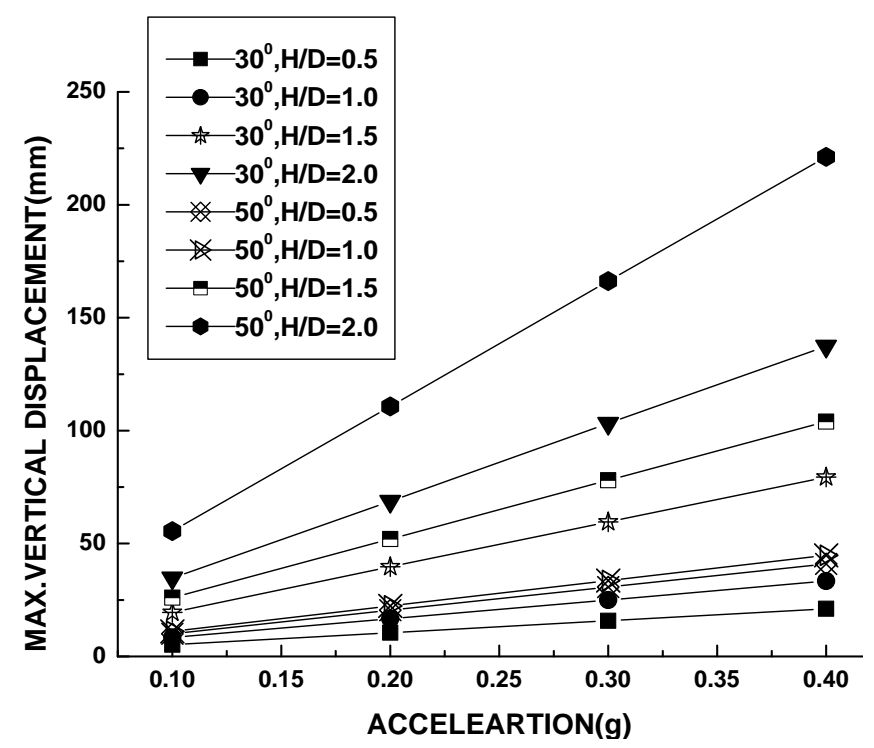

Fig 6: Variation of Max .Crest Displacement Vs Acceleration for Northridge Earthquake, $30^{\circ} \& 50^{\circ}$, medium clay

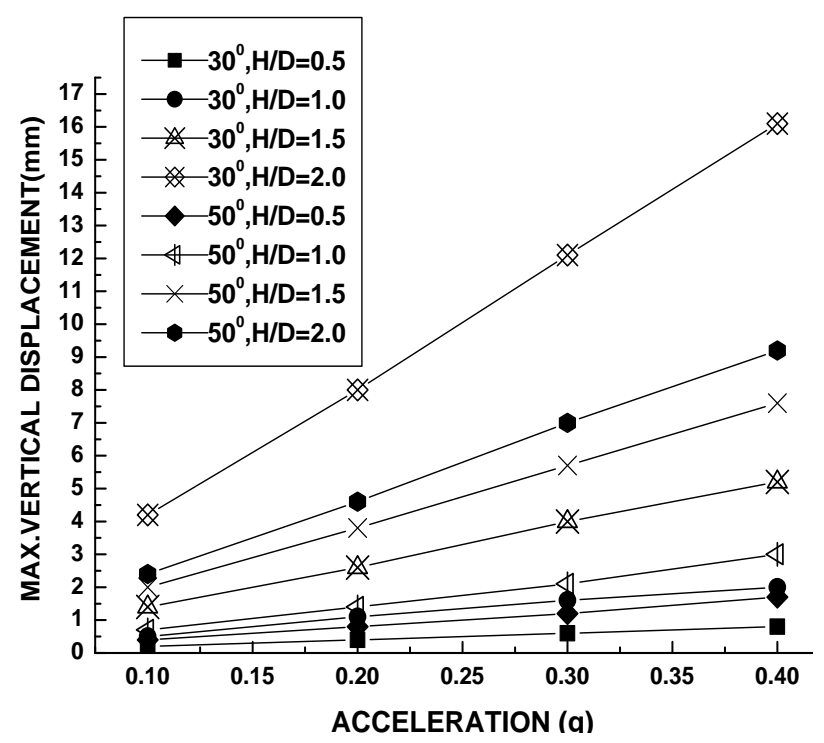

Fig 7: Variation of Max.Crest Displacement Vs Acceleration for Bhuj Earthquake, $30^{\circ} \& 50^{\circ}$, medium clay

Fig 7 shows the Variation of Max Crest Displacement Vs Acceleration for Bhuj Earthquake, $30^{\circ} \& 50^{\circ}$, Medium Clay. It is observed that increase in amplitude of acceleration increase in crest settlement. However, it is interesting to note that for $\mathrm{H} / \mathrm{D}$ ratio 2.0 for $30^{\circ}$ slope, maximum crest displacement is observed. This may be attributed to the close matching of the excitation frequency with the natural frequency of the embankment 
Table 2: Stability of soil slope of $5 \mathrm{~m}$ high

\begin{tabular}{|c|c|c|c|}
\hline Type of Soil & $\Phi$ in degrees & H/D ratio & Critical FOS \\
\hline \multirow{4}{*}{ Silty Sand } & \multirow{4}{*}{30} & 0.5 & $\begin{array}{l}0.9 \\
\end{array}$ \\
\hline & & 1.0 & 0.882 \\
\hline & & 1.5 & 0.863 \\
\hline & & 2.0 & 0.87 \\
\hline \multirow{4}{*}{ Medium Clay } & \multirow{4}{*}{30} & 0.5 & 2.544 \\
\hline & & 1.0 & 2.779 \\
\hline & & 1.5 & 2.592 \\
\hline & & 2.0 & 2.696 \\
\hline \multirow{4}{*}{ Silty Sand } & \multirow{4}{*}{50} & 0.5 & 0.561 \\
\hline & & 1.0 & 0.551 \\
\hline & & 1.5 & 0.527 \\
\hline & & 2.0 & 0.513 \\
\hline \multirow{4}{*}{ Medium Clay } & \multirow{4}{*}{50} & 0.5 & 17.01 \\
\hline & & 1.0 & 2.101 \\
\hline & & 1.5 & 20.53 \\
\hline & & 2.0 & 3.179 \\
\hline
\end{tabular}

\section{CONCLUSIONS}

A numerical study on the seismic response of slopes of silty sand and medium clay has been carried. The effect of ground motion parameters such as amplitude and frequency of vibrations on the response of these slopes were explored. Based on the present study the following conclusions may be drawn.

1. As the height of the slope increases the maximum crest displacement increases for the various type of soil. The sub soil condition effects the amplification of the slope.

2. As the slope angle increases, the crest settlement of the slope during dynamic loading increases and vice versa.

3. Increased crest settlements occur at increasing acceleration levels. The significant crest displacements are observed at the resonant frequencies.

\section{REFERENCES}

[1] Bray, J. D., and Rathje, E., [1998]. "Earthquake Induced Displacements of Solid Waste Landfills," Journal of Geotechnical and Geoenvironmental Engineering Vol. 124, GT 7, July 1998, pp. 242-253.

[2] Franklin, A. G. and Chang, F. K., [1977]. "Earthquake Resistance of Earth and Rock-Fill Dams." Report 5: Permanent Displacements of Earth Embankments by Newmark Sliding Block Analyses, Miscellaneous Paper S-71-17, Soils and Pavements Laboratory, U.S. Army engineer Waterways Experiment Station, Vicksburg, Mississippi

[3] Newmark, N. M., [1965]. "Effects of Earthquake on Dams and Embankments." Geotechnique, London, England, Vol. 5, No. 2, June 1965, pp. 139-160.

[4] Makdisi, F.I. and Seed, H. B., [1978]. "A Simplified Procedure for Estimating Dam and Embankment Earthquake-Induced Deformations." Journal of the
Geotechnical Engineering Division, ASCE, Vol. 104, No. GT7, July 1978, pp. 849-867.

[5] Jibson, R.W., [1993]. "Predicting Earthquake Induced Landslide Displacements Using Newmark's Sliding Block Analysis," Transportation Research Board, National research council, Washington, D.C.

[6] Martin, G.R., and Qui, P., [1994]. "Effects of Liquefaction on Vulnerability Assessment," NCEER Highway Project on Seismic Vulnerability of New and Existing Highway Construction, Year One Research Tasks - Tech. Research Papers

[7] ANSAL, A "Lecture Notes On Soil Dynamics"

[8] KRAMER, S.L. "Earthquake Geotechnical Engineering'" (1996)

[9] Design of Foundation in Sesmic Area: Principle and Application.

[10] Debabrata Giri, Aniruddha Sengupta (2009) "Dynamic Behaviour of small scale nailedsoil slopes", Geotechnical \& Geological Engineering 27: 687-698.

\section{BIOGRAPHIES}

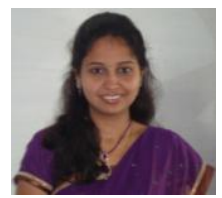

Mrs Rajani Shurpali graduated from UVCE, Bangalore Unversity and later did Post graduation in UVCE ,Bangalore University. Currently working as Assistant Professor in Sri Venkateshwar College of Engineering, Bangalore 562157.

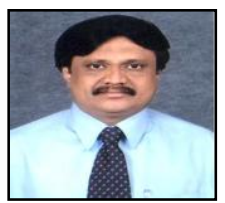

Dr. L.Govindaraju is currently Associate Professor, in the Department of Civil Engineering, UVCE, Bangalore University, and Bangalore. 